\title{
Experimental study of CFRP fluid-filled tubes subjected to high-velocity impact
}

\author{
D. Varas, R. Zaera, J. López-Puente* \\ Department of Continuum Mechanics and Structural Analysis, University Carlos III of Madrid. Avda. de la Universidad, 30,28911 Leganés, Madrid, Spain
}

\section{A R T I C L E I N F O}

\section{Keywords:}

Carbon fiber

Hydrodynamic Ram

Fluid-structure interaction

Fluid-filled tank

Impact

\begin{abstract}
A B S T R A C T
In recent years, vulnerability against high-velocity impact loads has become an increasingly critical issue in the design of composite aerospace structures. The effects of Hydrodynamic Ram (HRAM), a phenomenon that occurs when a high-energy object penetrates a fluid-filled container, are of particular concern in the design of wing fuel tanks for aircraft because it has been identified as one of the important factors in aircraft vulnerability. The projectile transfers its momentum and kinetic energy through the fluid to the surrounding structure, increasing the risk of catastrophic failure and excessive structural damage. For the present work, water-filled CFRP square tubes were subjected to an impact of steel spherical projectiles (12.5 mm diameter) at impact velocities of 600-900 m/s. The CFRP tubes were filled to different volumes to examine how volume might influence the tank behavior. The composite test boxes were instrumented with six strain gauges and two pressure transducers, and the formation process of the cavity was recorded using a high-speed camera. The damage produced in the tubes was then analyzed, and differences were found according to the testing conditions. This work presents the results of these tests.
\end{abstract}

\section{Introduction}

Aeronautic and aerospace industries are anticipating the design of lightweight structures to diminish fuel consumption, while maintaining the high safety and reliability that are required in engineering fields. Composite laminates are candidates to fulfill these requirements due to their high strength-to-weight and stiffness-to-weight ratios and to the flexible tailoring of their properties in a required direction. The most used composite materials for structural applications in these sectors are carbon fiber reinforced plastics (CFRP), commonly manufactured with an epoxy matrix that combines good mechanical properties, high resistance to corrosion and fatigue, and low density $\left(\rho=1500 \mathrm{~kg} / \mathrm{m}^{3}\right)$. CFRP applications in commercial aircraft, such as the fuselage and wings, have been steadily increasing [1] as raw material costs are reduced, automation of the manufacturing processes evolve and experience in design technology increases. Due to the usage of these materials in primary structures, it is necessary to understand how composites behave when they are subjected to different loads. During their service life, aircrafts are subjected to different types of loads; however, vulnerability against high-velocity impact loads is becoming an increasingly critical issue for the design of CFRP aerospace structures in recent years. Bird strikes [2] and hailstones [3] are examples of impact situations that are considered due to the high probability of occurrence and disastrous consequences, particularly when ingested by the engine. Also, the ice released from the

\footnotetext{
* Corresponding author. Fax: +34 916248331.

E-mail address: jlpuente@ing.uc3m.es (J. López-Puente).
}

edge of a propeller blade may impact the nacelle of the twin engine or the fuselage, and runway debris may impact the underside of the wing structures [4]. The study of the behavior of composite laminates under high-velocity impact has received attention since the 1970 s, when only military research agencies were concerned about this subject. In the 1980s, investigators from civil organizations began to publish articles in which the breakage mechanism of such materials under ballistic impact was investigated primarily from an experimental approach [5-7]. Later, both analytical [813] and numerical [14-20] approaches were used to predict the energy absorbed by the laminate and the damaged area after a penetrating impact.

One of the most important factors in aircraft vulnerability is the effect of the Hydrodynamic Ram (HRAM) phenomenon, which occurs when a high-energy object penetrates the fuel tanks inside the wings because these represent the largest exposed area of all the vulnerable components. An example of the importance of this phenomenon is the Concorde accident that occurred in 2000. The final investigation report revealed that the HRAM had played a significant role in the aircraft failure. Other types of projectiles that may impact aircraft structures include small and medium caliber bullets and fragments due to a blast, both of which cause HRAM effects when they impact the fuel tank of an airplane or a helicopter. The aeroengine turbine blade may also fail due to fatigue and may penetrate the wall of the containment cell, damaging oil tanks and airframes [21]. HRAM is particularly dangerous for aircraft with lightweight designs because the structural resistance of their integral fuel tanks cannot be improved by strengthening the airframe. Strengthening the frame would counteract the requirements of a lightweight design. 


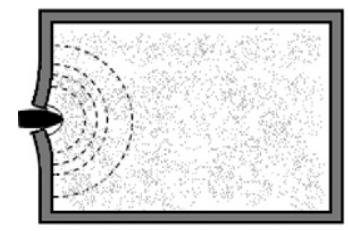

SHOCK

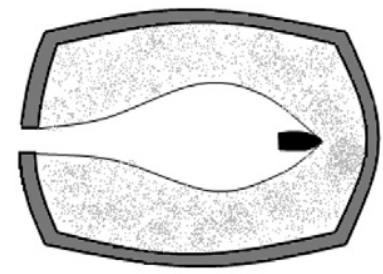

CAVITATION

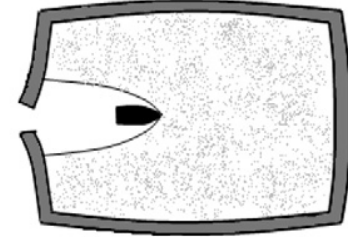

DRAG

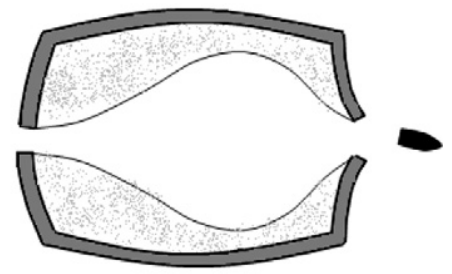

EXIT
Fig. 1. The phases of Hydrodynamic Ram.

Hydrodynamic Ram consists of four principal stages: shock, drag, cavitation and exit (Fig. 1). Each stage contributes to structural damage through a different mechanism and to a different extent. When the projectile penetrates the wall of the fluid filled structure, the impact energy is transferred to the fluid and generates a high-pressure hemispherical shock wave. This leads to damage primarily in the vicinity of the impact position. During the drag phase, the projectile travels through the fluid, and its kinetic energy is partially transformed into fluid motion as the projectile is slowed by viscous drag. The displacement of the fluid from the projectile path generates a radial pressure field. In contrast to the pressure field developed during the shock phase, the fluid is accelerated gradually rather than impulsively. This causes less intense peak pressures, but they are of greater temporal extent. The displacement of fluid during the drag stage forms a cavity behind the projectile. The subsequent expansion and collapse (oscillations) of the cavity is known as the cavitation stage. The oscillations of the cavity can cause significant pressure pulses. The final stage of Hydrodynamic Ram occurs when the projectile exits the container. In contrast to the perforation of the front wall, the exit of the projectile occurs through a pre-stressed wall. The pre-stress is caused by the initial shock stage and the subsequent loading by the fluid.

The military industry has always been interested in the protection of the fuel tanks. In the 1970s, various groups within the US Defense Department expended a considerable research effort to achieve a better understanding of the HRAM phenomenon and the associated fluid-structure interaction problem. The Naval Weapons Center (NWC, China Lake, California) conducted an interesting Hydrodynamic Ram project, in which a series of ballistic tests were performed to obtain fluid pressure measurements at several locations for a variety of projectiles [22]. At the same time, the Naval Postgraduate School (NPS) conducted an analytical and experimental Hydrodynamic Ram program in conjunction with the NWC project. Fluid pressures and entry-wall strains were measured for various projectile sizes and energy levels. The tests and their results are reported in [23-33]. The University of Dayton Research Institute also performed several impact experiments on fuel tanks during the 1970s. Bless et al. [34] completed experiments using spherical projectiles of 11.1 and $14.3 \mathrm{~mm}$ diameter with a velocity range of $1.5-2.4 \mathrm{~km} / \mathrm{s}$ and obtained data for the entrance and side panel displacement, fluid pressure and the projectile trajectory. In all the mentioned works, the fluid-filled container existed on a structure on which different metallic panels could be placed and the top of the tank was always open.

One of the first public works in which composite fuel tanks were studied corresponds to the Advisory Group for Aerospace Re- search and Development. Impact tests were conducted in 1988 to study the influence of projectile shapes, fluids, and impact angles on aluminum and carbon epoxy tanks [35]. The conclusions included that the shape of the fragment may have a substantial effect on the HRAM structural response of a fuel tank and that the stitching of stiffeners to the panels provided transverse reinforcement and resistance to the propagation of the delamination damage. It was also observed that the severe structural damage of the graphite/epoxy exit panels was concentrated in the vicinity of the fragment perforation sites, whereas the severe damage of the entry panels was in the vicinity of both of the panel joints and the fragment perforation sites.

In recent years, interest in the study of the HRAM phenomenon has increased [36-41]; however, the number of papers concerned with the impact response of CFRP fuel tanks is small. Nearly all of the above experimental works employed tanks with a metallic structure, which exhibits a ductile behavior compared to carbon fiber composites. Furthermore, previous works were completed with open containers, and the behavior could vary significantly from that of a closed tank, as in the case of a fuel tank. Lastly, the influence of different fluid volumes on the behavior of a CFRP closed container should be studied to assess its importance.

In the present work, experiments were performed on waterfilled CFRP square tubes subjected to impact velocities of 600$900 \mathrm{~m} / \mathrm{s}$ by steel spherical projectiles $(12.5 \mathrm{~mm}$ diameter). The CFRP tubes were filled to different fluid volumes to study how the volume influenced the tank behavior. The test boxes were instrumented with six strain gauges and two pressure transducers. The process of cavity formation was recorded with a high-speed camera. This work presents the results and analysis of these tests.

\section{Experimental setup}

Impact tests, in which a projectile penetrates into a fluid-filled container, were performed. The schematic of the experimental devices used in the tests is shown in Fig. 2.

\subsection{Specimen assembly and instrumentation}

The specimens impacted by the projectiles were square CFRP tubes with the following dimensions: $150 \mathrm{~mm}$ wide, $2.2 \mathrm{~mm}$ thick, and $750 \mathrm{~mm}$ long. The specimens were chosen as a representative structural element of a type of fuel cell inside airplane wings to analyze the HRAM effects. The specimens were closed with two PMMA windows that were $30 \mathrm{~mm}$ thick and stiff enough to minimize bending and to avoid image distortion because these transparent panels allowed for the recording of the impact process. The PMMA windows were fixed to the specimen using four steel bars that assured contact between the tube and the PMMA. A similar setup was proposed by Nishida et al. [42]. The contact points between the PMMA windows and the specimen were sealed using silicone to avoid fluid leakage, as shown in Fig. 3. The tubes were filled with water to different volume fractions: $60 \%, 75 \%$, and $100 \%$.

The pressure on the fluid and the strain on the composite walls were measured using two pressure transducers and six strain gauges. The pressure pulse was recorded with a PCB 138A06 sensor [43] with a measurement range of $34.4 \mathrm{MPa}$ and a resolution of $0.07 \mathrm{kPa}$. Two holes were made in the lower wall of the specimen to place both sensors within the water. The positions of the pressure gauges (PTn and PTf) are shown in Fig. 4, and a lateral view of the gauges inside of the specimen is shown on the right side of Fig. 5. The strain pulses were measured using uniaxial gauges (350 $\Omega$ and 2.120 Gage factor) from Vishay Measurements Group Inc. Two gauges were located on the entry wall, G1 and G2 (see Fig. 5 left), another two were located on the exit wall, G3 and G4, at the same posi- 


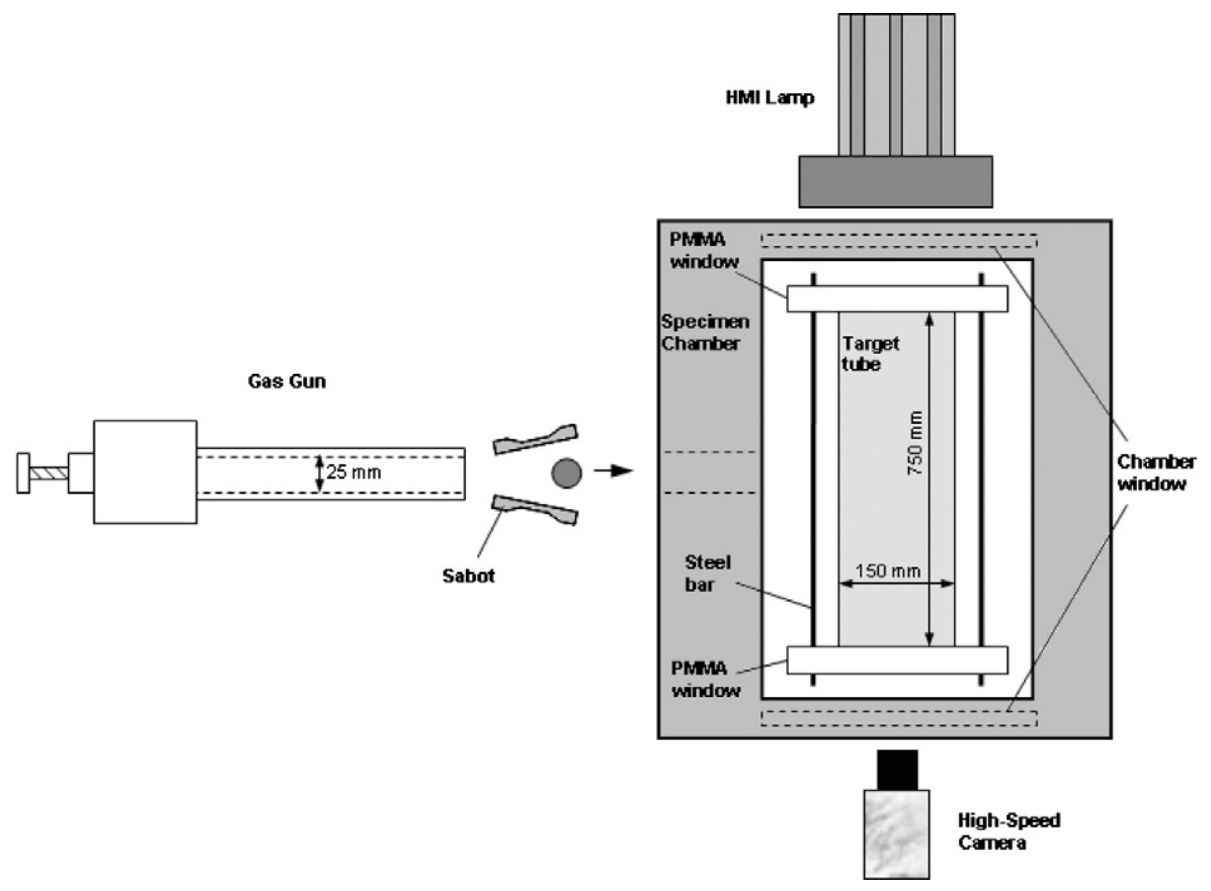

Fig. 2. The schematic of the experimental setup.

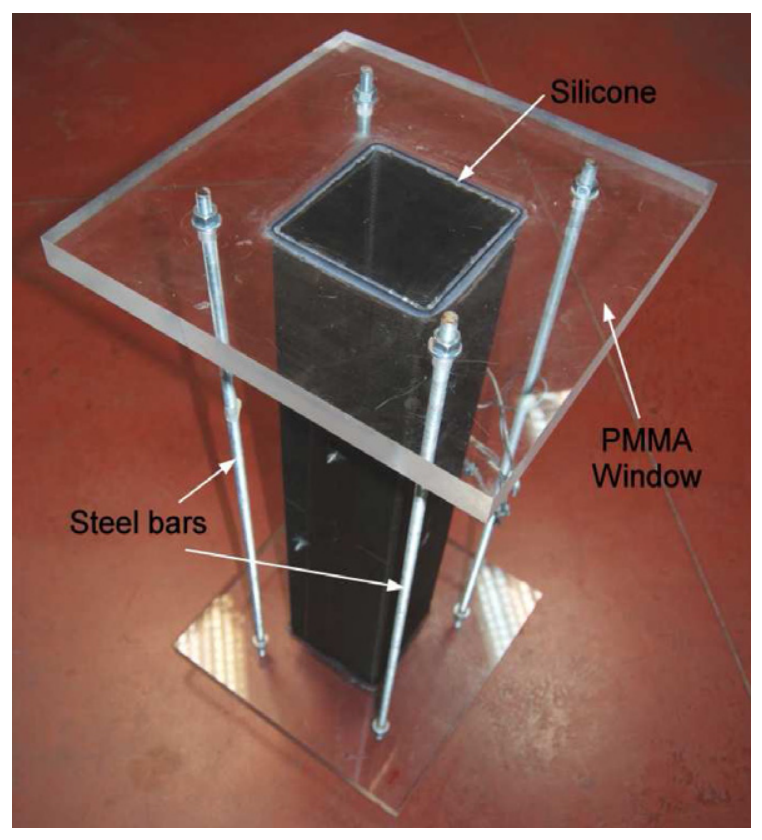

Fig. 3. The closed test box.

tion as the entry gauges, and finally two gauges, G5 and G6, were located on the lower and upper wall, respectively, as shown in Fig. 4. Using this setup, the impact influence on different tube zones was found. A Dewetron DEWE-800 data-acquisition device was used to record all of the signals. This system recorded at a sampling rate of $1 \mu \mathrm{s}$ and synchronized the data with the video recording.

\subsection{Gas gun and specimen chamber}

The projectiles that impacted the CFRP specimens were accelerated using a one-stage light gas gun that has a 4.71 chamber capable of storing gas at a maximum pressure of 300 bar. The gas gun was used with helium due to its low density. The length of the bar- rel was $4.5 \mathrm{~m}$, and its caliber was $25 \mathrm{~mm}$. The gun was aimed at an armored steel specimen chamber box that was $1 \times 1 \times 1 \mathrm{~m}^{3}$ in which the specimen was placed during the impact test. The distance between this chamber and the tip of the barrel was $3.0 \mathrm{~m}$. The chamber had a small circular window located in the front through which the projectile passed to impact the specimen, and two large lateral windows illuminated the specimen and captured the video sequence of the impact (Fig. 2).

\subsection{Projectile}

The projectile used in the impact tests was a steel sphere with a diameter of $12.5 \mathrm{~mm}$ and a mass of $8 \mathrm{~g}$. Because the gas gun caliber was larger than the projectile diameter, a sabot was required to launch the projectile. Different sabots were designed and tested to ensure a minimum weight and that the valves opened prior to reaching the target chamber without influencing the impact tests. Finally, a PVC sabot with two valves weighing $21 \mathrm{~g}$ was used at two impact velocities: 600 and $900 \mathrm{~m} / \mathrm{s}$.

\subsection{High speed camera and lighting system}

A Photron Ultima APX-RS digital high-speed camera was used to record the projectile penetration into the fluid and the development of the cavity. The selected frame rate was 36,000 frames per second, a frame was captured every $27.7 \mu$ s. The resolution was $384 \times 160$ pixels, and the shutter was set to $1 \mu \mathrm{s}$. These settings were selected based on early testing and represent an optimal tradeoff between the available lighting and the minimization of blur in the images. Lighting was provided by an Arrisun 12 Plus lamp head with a $1200 \mathrm{~W}$ Hydrargyrum Medium-arc Iodide (HMI) lamp.

\section{Experimental results}

\subsection{Impact process}

Figs. 6 and 7 correspond to two sequences recorded during some of the impact tests and demonstrate how the projectile penetrates the fluid, creating a cavity behind it as it travels through the 


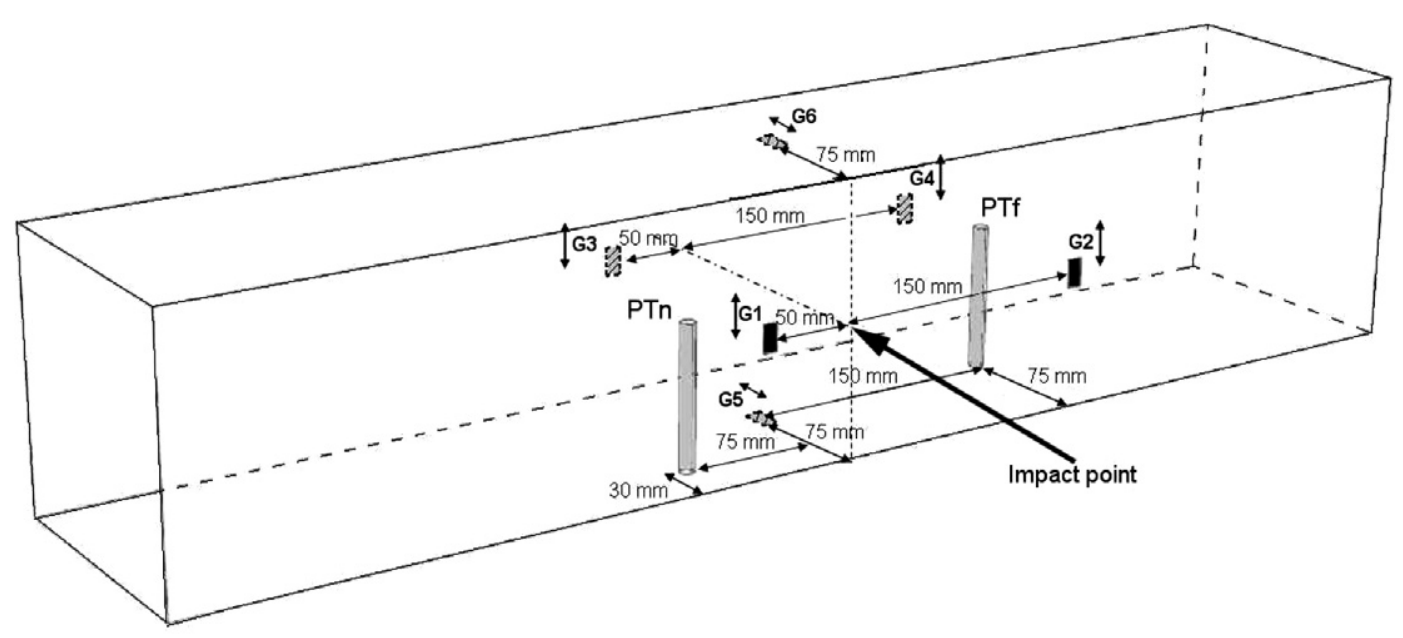

Fig. 4. The schematic of the test box instrumented.
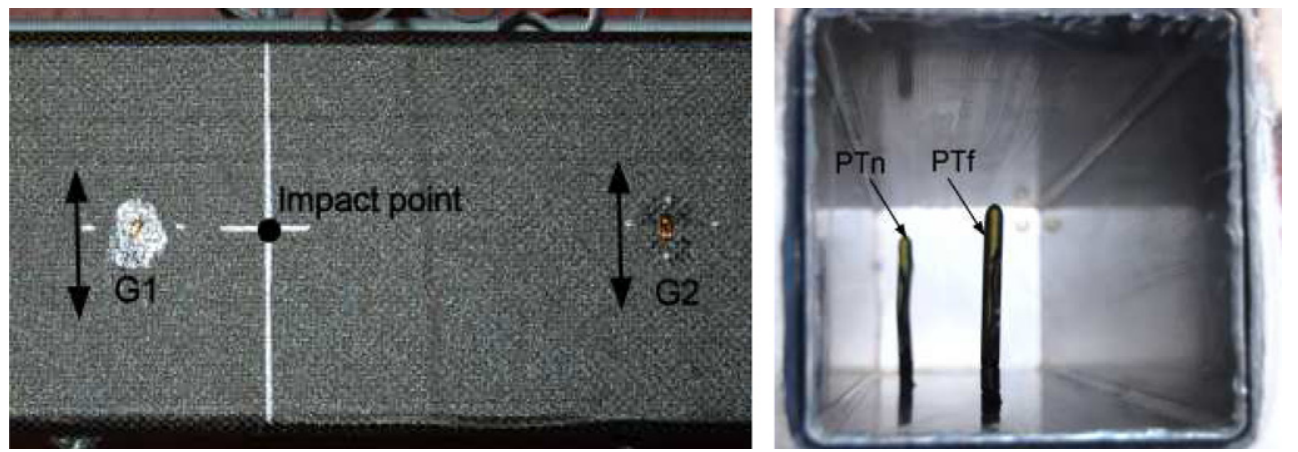

Fig. 5. Left: Detail of the strain gauges located in the entry wall of the specimen. Right: Lateral view of the pressure transducers inside the specimen.

water. Because the penetration of the projectile into the fluid is subsonic, spherical wave fronts propagating in the same direction of the projectile and their rarefactions with the test box can be detected in the pictures. In the partially filled cases, it can be seen that the cavity raises the free surface of the fluid, and a layer of fluid accelerates upwards (Fig. 7). This layer will impact the upper wall of the box at high velocity causing failure, as will be shown later. Fig. 7 reveals the rarefaction wave that was formed at the free surface of the fluid following the initial wave. As a result, the pressure drops drastically in the fluid, and bubbles appear behind the rarefaction wave.

In addition to showing the cavity evolution, the digital highspeed camera provided a means to determine the velocity and the position of the projectile inside of the fluid. These experimental data is compared with analytical results (Fig. 8) that are obtained from Newton's second law:

$m_{p} \frac{d V_{p}}{d t}=-\frac{1}{2} \rho_{w} A_{0} C_{d} V_{p}^{2}$

where $m_{p}$ and $V_{p}$ denote the projectile mass and velocity, $\rho_{w}$ is the fluid density, $A_{0}$ is the projected frontal area of the projectile and $C_{d}$ is a dimensionless drag coefficient. To correspond with the range of velocities considered, a value of 0.4 for $C_{d}$ was chosen [44].

The projectile position is well known by means of the video, and it can be seen that its values correspond with the analytical curves. The velocity values determined with the camera do not correspond exactly with the velocity at each point because they are calculated as an average between two frames. Therefore, there are differences among the experimental and analytical data. Nevertheless, the same trends are noted. As a result of the decay in the velocity of the projectile, the kinetic energy is progressively converted into pressure and kinetic energy in the fluid, which will produce deformation of the composite structure.

\subsection{Pressure time history}

As mentioned above, two pressure gauges were used to record the time history of the HRAM pressure wave as it propagated through the fluid. One of the pressure gauges (PTn) was located near the impact point at $30 \mathrm{~mm}$ from the wall and $75 \mathrm{~mm}$ from the shot line, while the other (PTf) was in the middle of the tube at $150 \mathrm{~mm}$ from the projectile trajectory and measured the pressure in a point far from the impact zone (Fig. 4). The pressure time histories depicted in Fig. 9 represent the typical curves found for pressure measurements at PTn and PTf at different impact velocities and volume percentages. The pressure in PTn begins to increase approximately $60 \mu$ s after the impact, while PTf begins to measure at approximately $120 \mu \mathrm{s}$. These data correspond with the times calculated according to the position of the pressure transducers and the wave speed in water. As shown in these curves, the pressure time history changes as a function of the location of the pressure gauge and the velocity of the projectile. The maximum pressure is highly sensitive to the projectile velocity, with the peak pressure at $900 \mathrm{~m} / \mathrm{s}$ double that reached at $600 \mathrm{~m} /$ s. Consequently, it is expected that velocity will strongly affect the damage and failure of the CFRP tube. The influence of the sensor position in the pressure data is justified by the fact that 

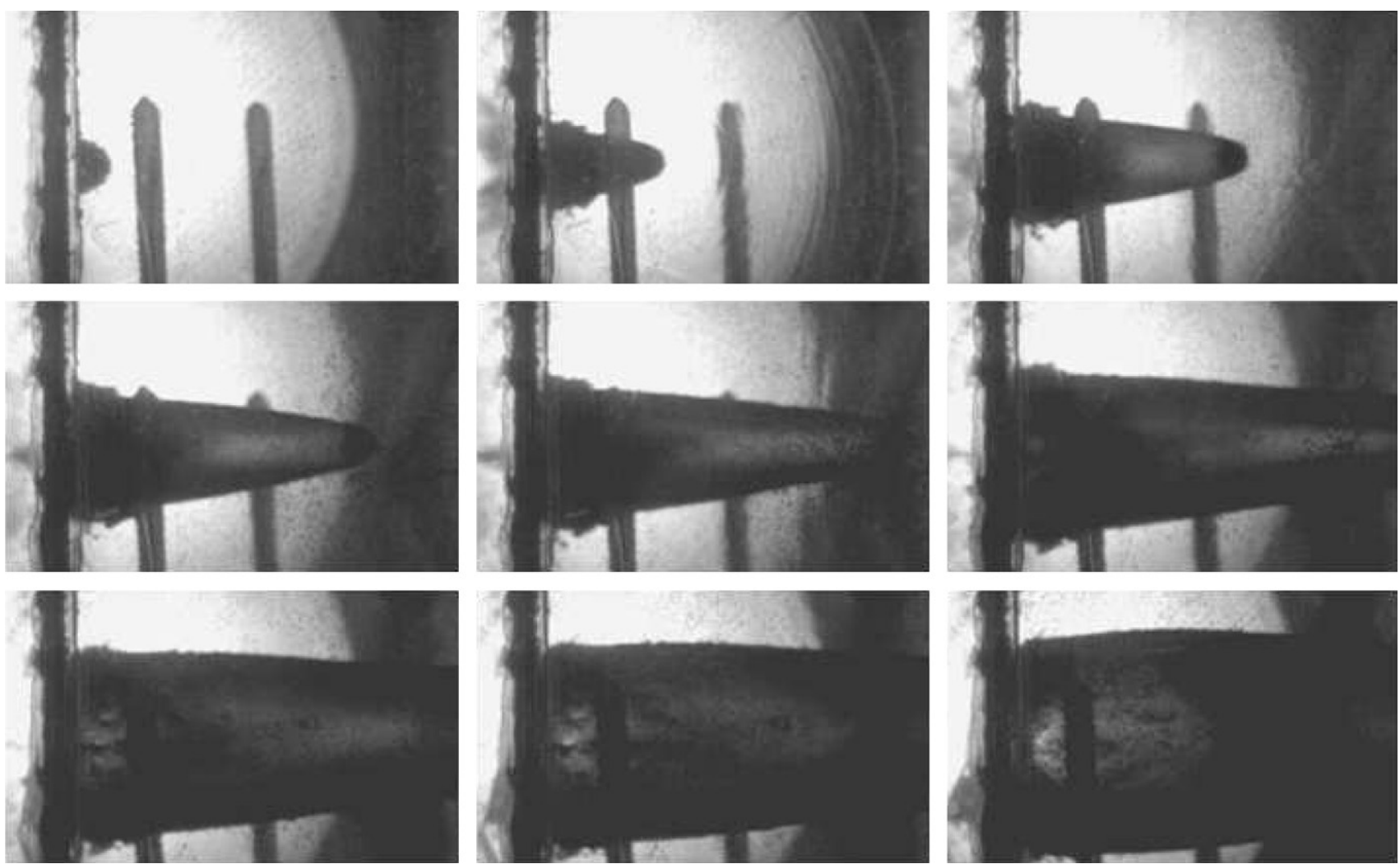

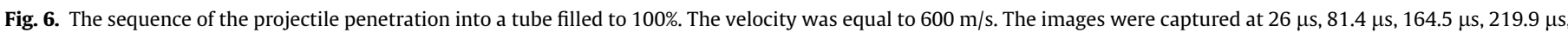
$275.3 \mu \mathrm{s}, 413.8 \mu \mathrm{s}, 552.3 \mu \mathrm{s}, 663.1 \mu \mathrm{s}, 857 \mu \mathrm{s}$. Time $t=0$ corresponds to initial contact.
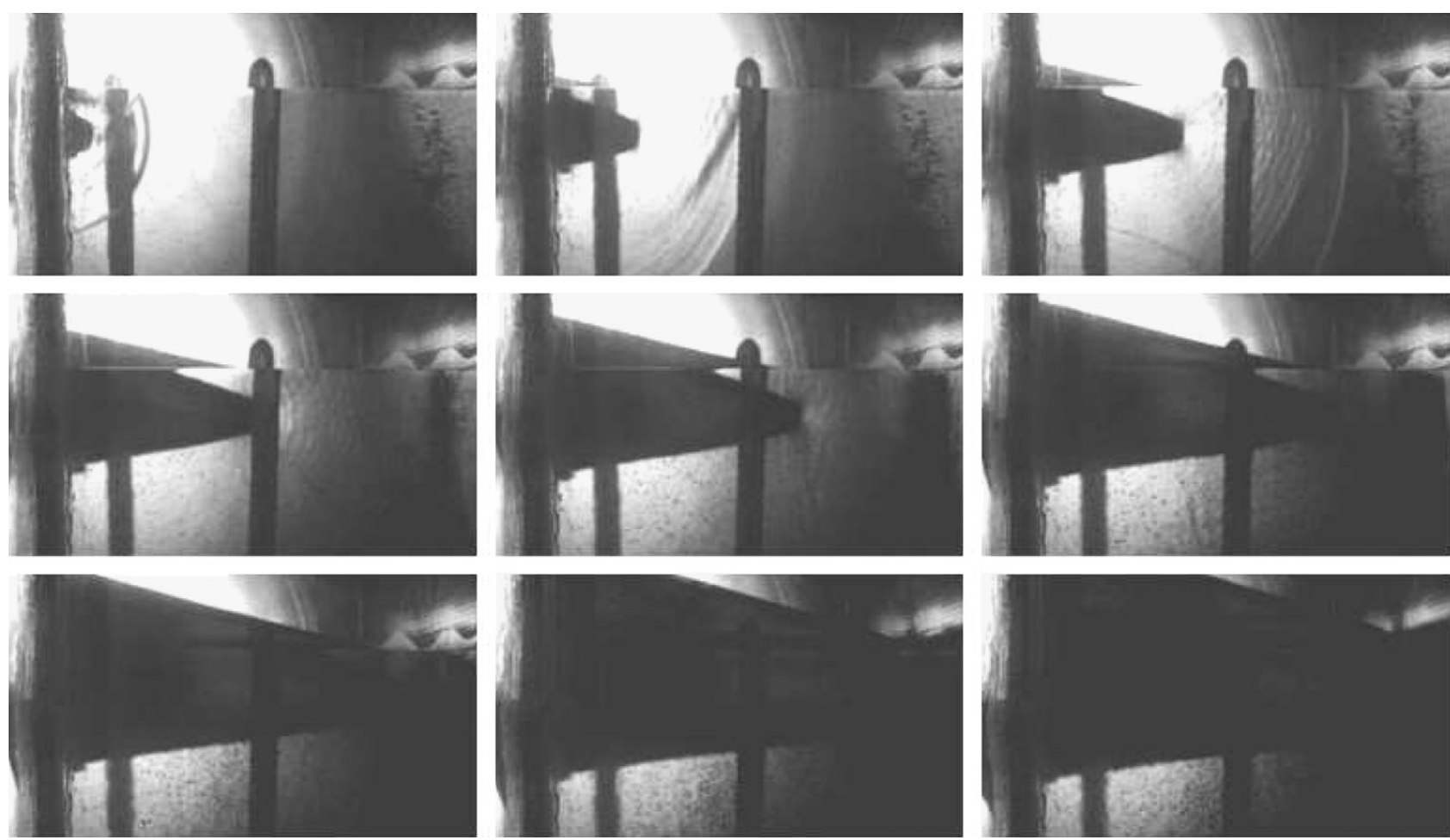

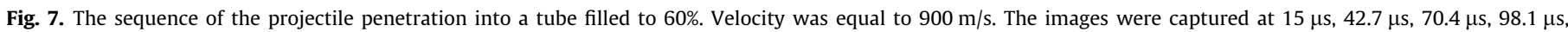
$125.8 \mu \mathrm{s}, 153.5 \mu \mathrm{s}, 181.2 \mu \mathrm{s}, 236.6 \mu \mathrm{s}, 264.3 \mu \mathrm{s}$. Time $t=0$ corresponds to initial contact.

the energy of a spherical pressure wave decreases with the square of the distance from the source.
Regarding the filling percentage, the main difference observed is the duration of the pressure pulse, which decreases as the fluid 

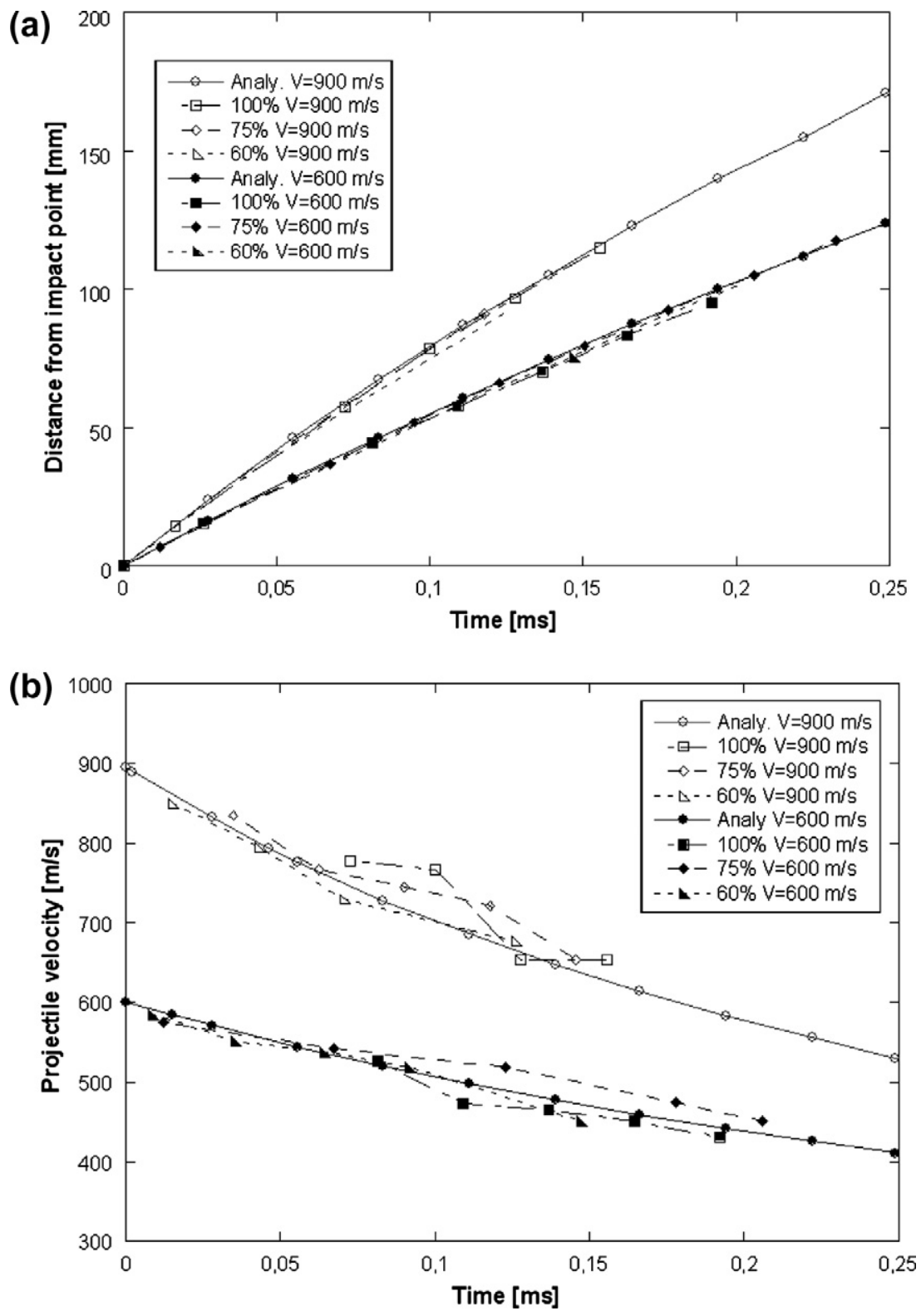

Fig. 8. (a) Comparison of the position of the projectile vs. time. (b) Comparison of the velocity decay vs. time.

level falls (Fig. 9). This is due to the effect of the rarefaction wave formed at the free surface [40].

\subsection{Strain time history}

Once the projectile impacted the fluid-filled tank and the pressure waves passed through the fluid, the cavity begins to grow due to the advance of the projectile, which moves the fluid out its path. This increase in the inner volume forces the tube to deform causing its failure. The rate of growth of the cavity depends largely on the impact velocity; the acceleration of the fluid particles towards the walls of the tube increases with the velocity of the projectile [40]. The kinetic energy of the fluid is transferred to the walls, deforming and damaging them. Therefore, the impact velocity may influence the damage and failure of the tube. In contrast, an incomplete filling of the tube allows the fluid to expand through the unfilled volume. Therefore, it could be concluded that a lower filling percentage will lead to less damage of the tube. However, it will be shown that this is not always true.
As previously mentioned, two strain gauges were located on the impact wall, G1 and G2 (Fig. 4). The exit wall was instrumented with two strain gauges, G3 and G4, located in the same positions as G1 and G2 with respect to the projectile trajectory. Finally, two strain gauges, G5 and G6, registered strains in the middle of the lower and upper wall of the specimen, respectively (Fig. 4). Fig. 10 depicts the strain data at gauge G1, the closest gauge to the impact site, for the various tests performed. It must be mentioned that the positive sign associated with the strain data indicates that the wall is displaced outwards. It is observed that some signals are no longer valid shortly after the initial contact. This is most likely due to the violent shake of the tube caused by the impact and to the peeling of the outer plies that may induce the debonding of the gauges. Although Fig. 10 does not show a clear trend, it can be seen that in a completely fluid-filled tube, the maximum strain and hence, the breakage, are reached later when the impact is at lower velocity.

Fig. 11 shows data from $\mathrm{G} 3$, the closest gauge to the impact point in the exit wall, for the different tests performed. The signals 

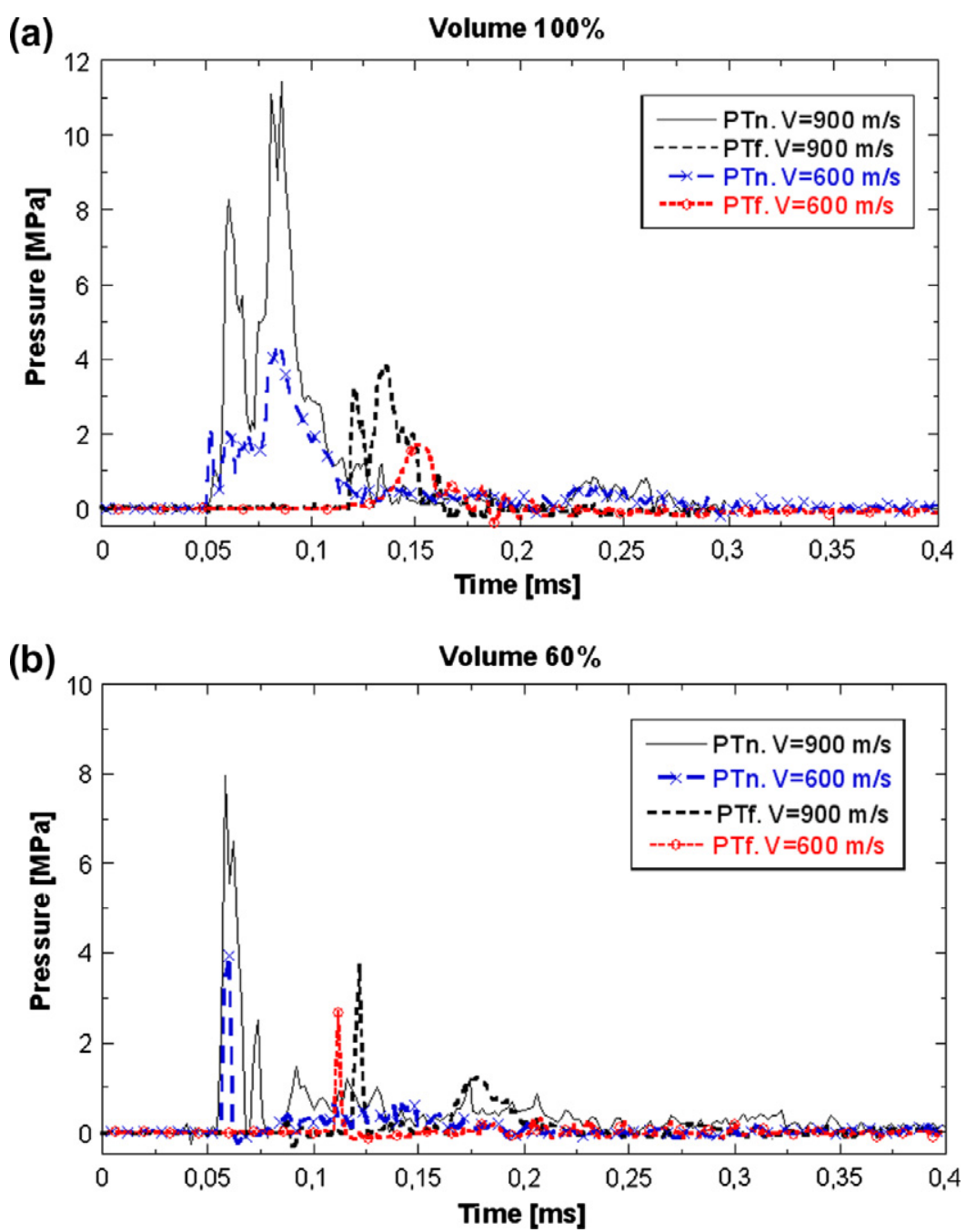

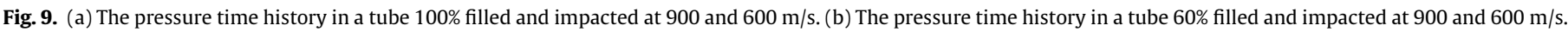

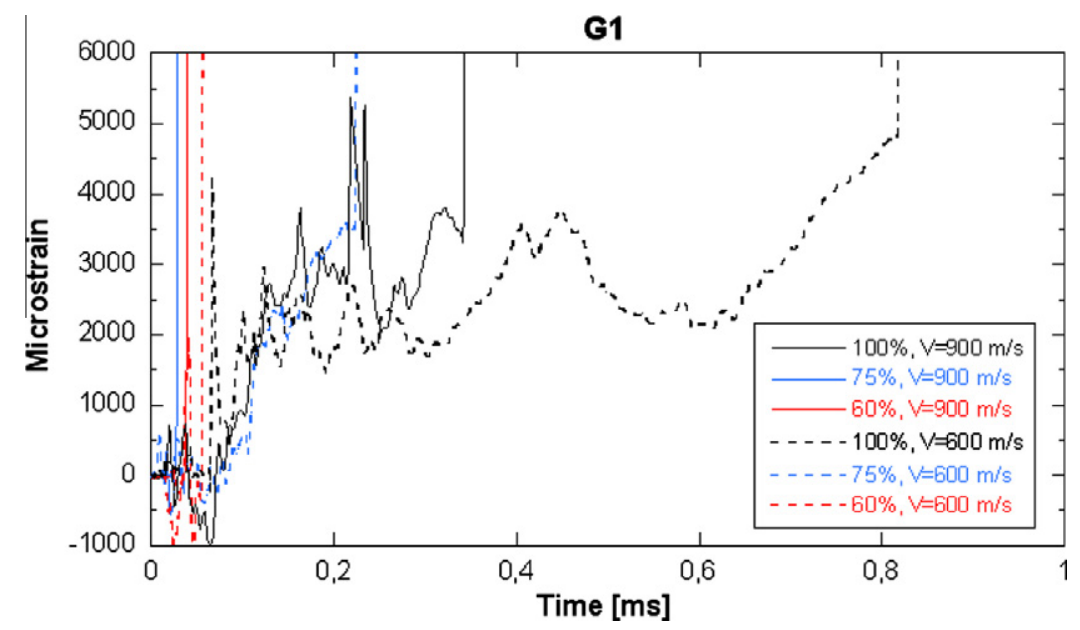

Fig. 10. The strain time history in G1 (entry wall) for various testing conditions.

that correspond to impacts at $900 \mathrm{~m} / \mathrm{s}$ are no longer valid at approximately $0.3 \mathrm{~ms}$. At approximately $0.25 \mathrm{~ms}$, the projectile impacts and perforates the exit wall creating a hole. Because the wall is loaded by the pressure in the fluid, this hole triggers a cross shaped breakage that affects the strain gauges (Fig. 12). Regarding the impact at $600 \mathrm{~m} / \mathrm{s}$, although the signals seem to be valid for a longer time, different behavior exists between the $60 \%$ filled case and the cases of $100 \%$ and $75 \%$ filled. This is due to the longitudinal 


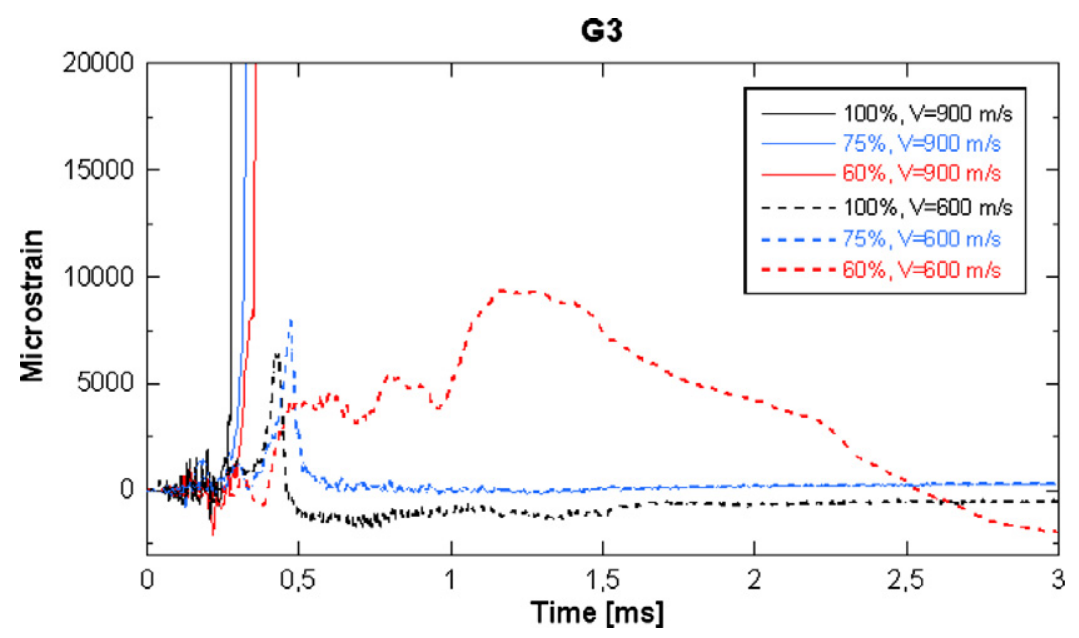

Fig. 11. The strain time history from G3 (exit wall) for different testing conditions.

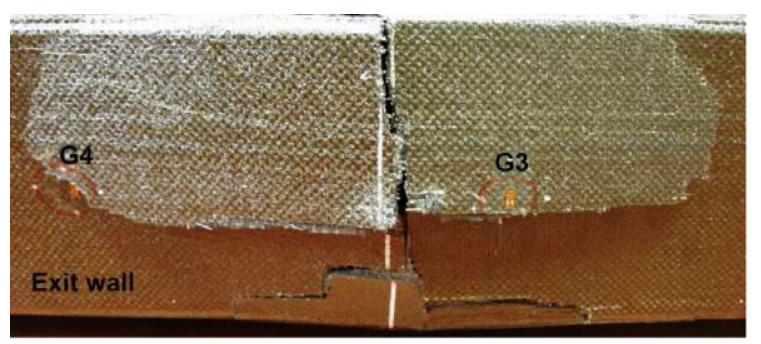

(a) $100 \%, V=900 \mathrm{~m} / \mathrm{s}$

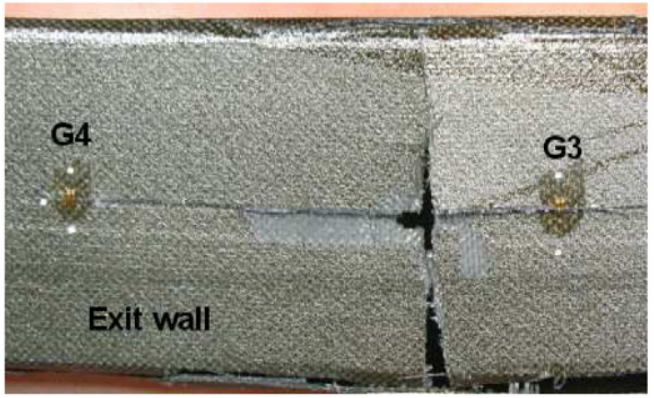

(c) $75 \%, \mathrm{~V}=900 \mathrm{~m} / \mathrm{s}$

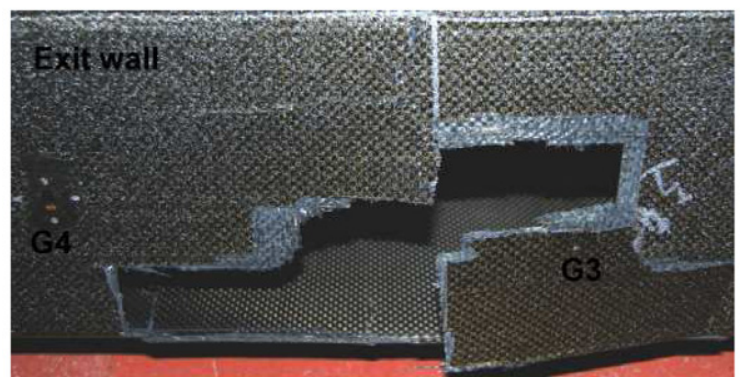

(e) $60 \%, \mathrm{~V}=900 \mathrm{~m} / \mathrm{s}$

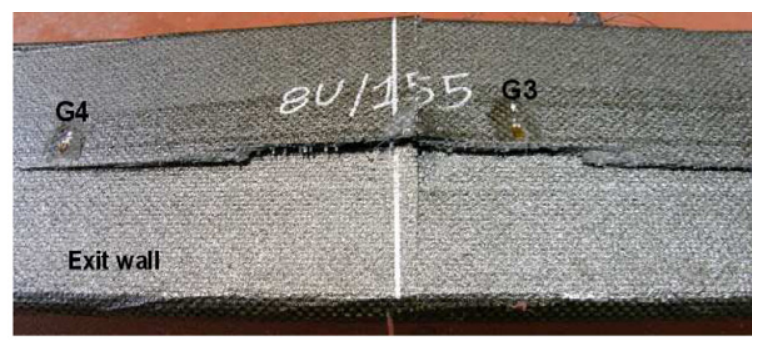

(b) $100 \%, \mathrm{~V}=600 \mathrm{~m} / \mathrm{s}$

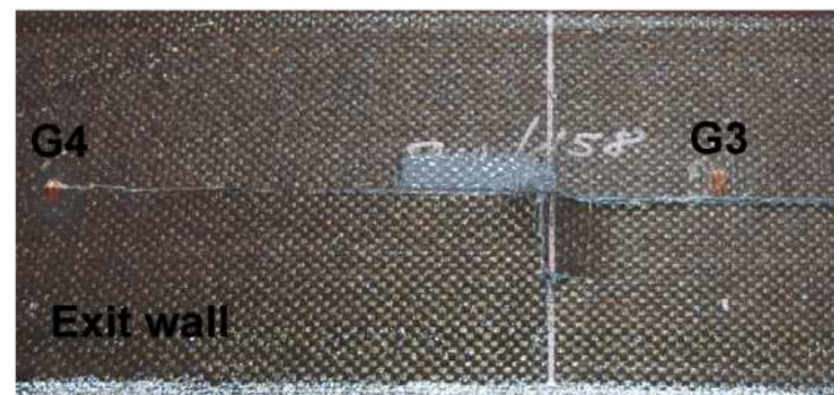

(d) $75 \%, \mathrm{~V}=600 \mathrm{~m} / \mathrm{s}$

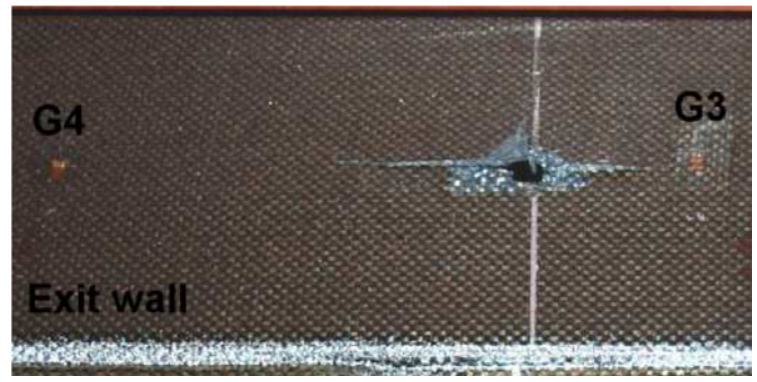

(f) $60 \%, V=600 \mathrm{~m} / \mathrm{s}$

Fig. 12. The detail of the exit wall breakage for different testing conditions.

crack of the cross-shaped breakage generated by the impact spreading below the gauges (without breaking them) in the $100 \%$ and $75 \%$ filled cases, causing the strain signal diminish quickly (Fig. 12b and d). However, the longitudinal crack does not reach the gauge in the $60 \%$ case (Fig. 12f). Fig. 13 depicts the data from G3 over a smaller time interval. The exit wall is partially pre-stressed before the projectile impacts it, which occurs at $t=0.25 \mathrm{~ms}$ with $V=900 \mathrm{~m} / \mathrm{s}$ and at $t=0.4 \mathrm{~ms}$ with $V=600 \mathrm{~m} / \mathrm{s}$, due to the pressure wave generated by the HRAM. It seems that the strains are primarily influenced by the impact velocity and then by the filling percentage; therefore, a high-impact velocity produces a premature failure of the gauge. For a given impact 
G3

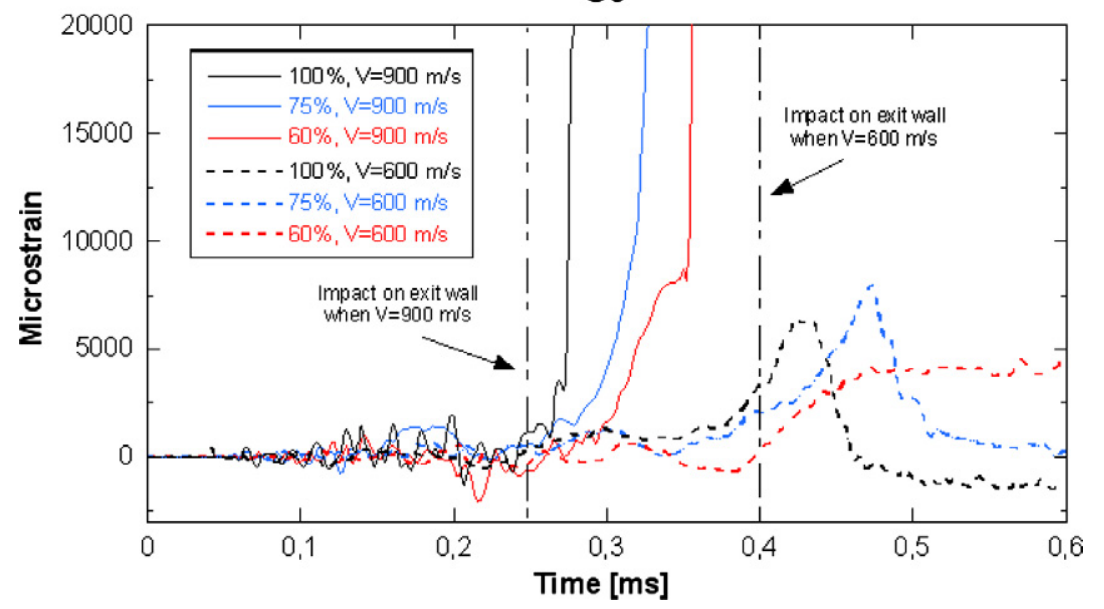

Fig. 13. Detail of the strain time history in G3 (exit wall) for various testing conditions.

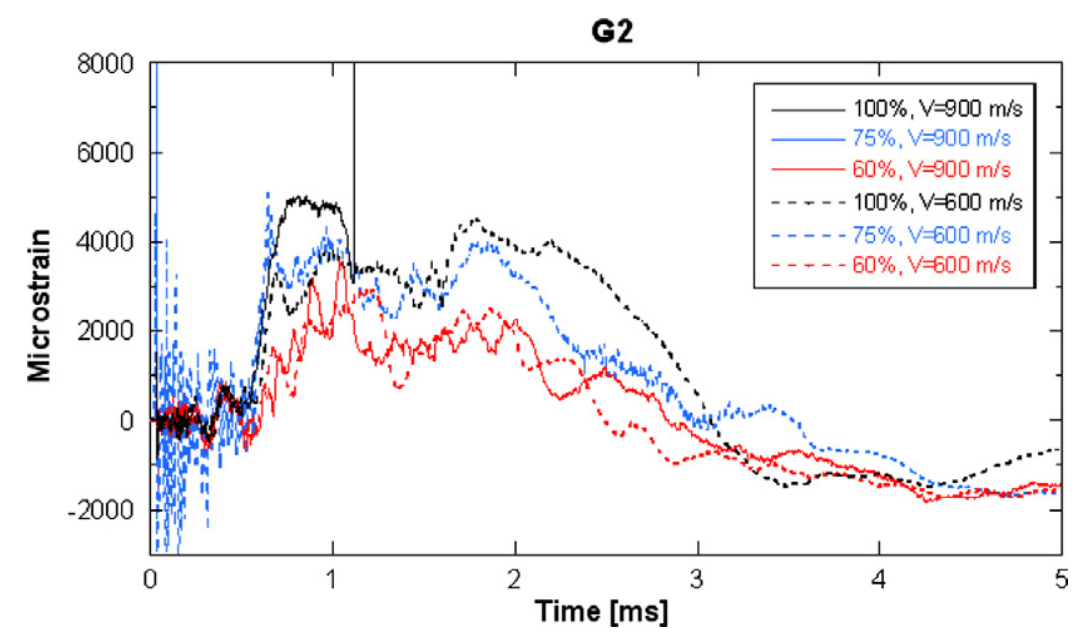

Fig. 14. Strain time history in G2 (entry wall) for various testing conditions.

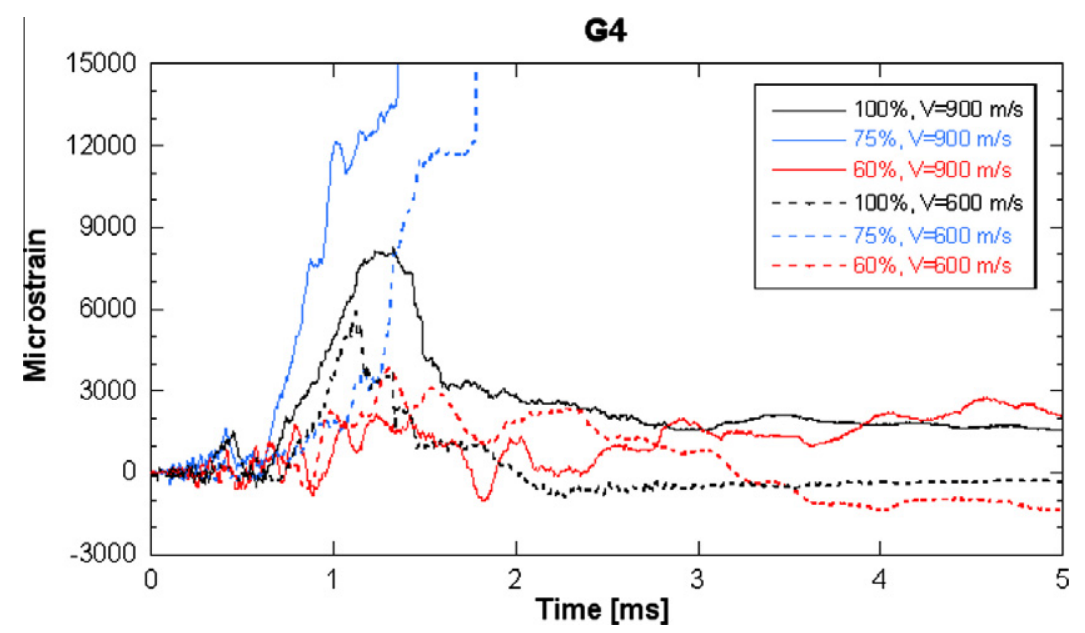

Fig. 15. Strain time history in G4 (exit wall) for various testing conditions.

velocity, the strain signals near the impact point are delayed when the tube contained less fluid because the pressure waves affects a smaller wall area and the fluid can freely move upwards.
The strain-time history far from the impact point in the entry and exit walls (G2 and G4) is depicted in Figs. 14 and 15, respectively. The data on the entry wall seem to be grouped together 
G5

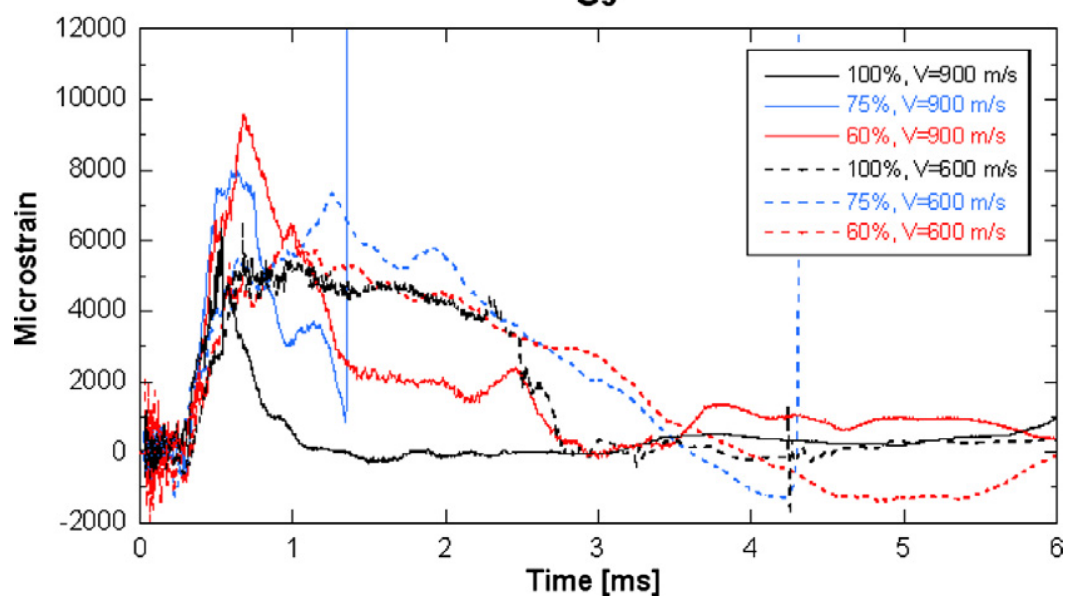

Fig. 16. The strain time history in G5 (lower wall) for various testing conditions.

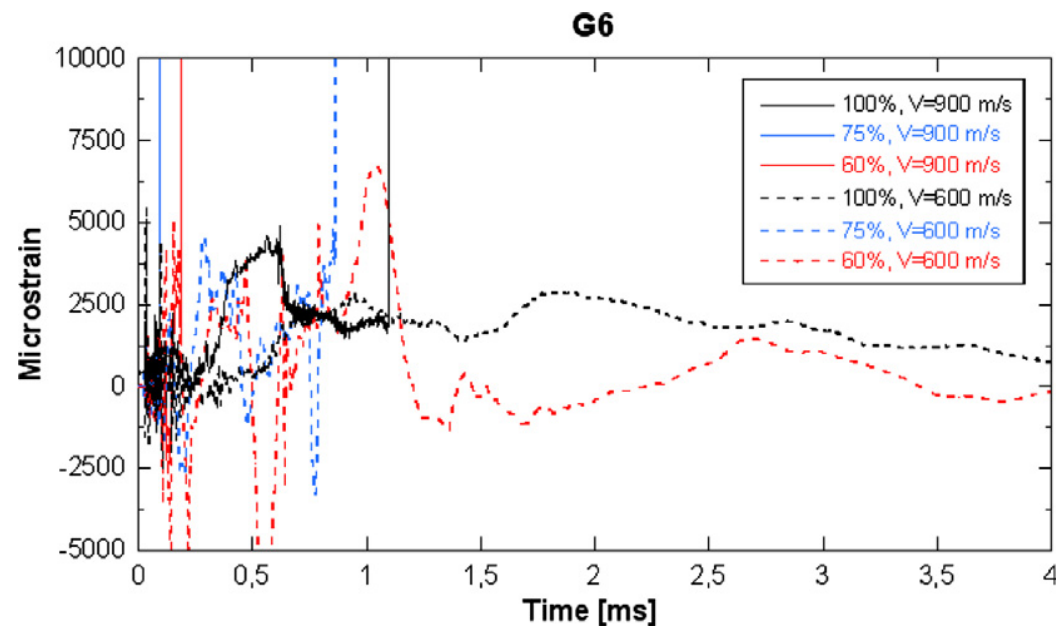

Fig. 17. The strain time history in G6 (upper wall) for various testing conditions.

by the filling percentage because the strains corresponding to the completely filled tubes (impacted at $900 \mathrm{~m} / \mathrm{s}$ and $600 \mathrm{~m} / \mathrm{s}$ ) are higher than those at $75 \%$ and $60 \%$ filled. Therefore, if far enough from the impact area, the strains measured are larger for a completely filled tank than for a partially filled one, although the latter were impacted at a higher velocity than the former. This was also observed in the aluminum tubes [40]. It is worth mentioning that due to the cross shaped breakage produced in the exit wall, some of the strain gauges (G4) were affected by the longitudinal crack (Fig. 12); therefore, the trend observed in the exit wall is not as clear.

The strain-time history for the middle of the lower wall and directly below the trajectory of the projectile (G5) is shown in Fig. 16. The strain values are primarily influenced by the velocity because the higher strains are grouped together by velocity. When the tubes are impacted at a lower velocity, the maximum strain is reached at a later time.

Finally, Fig. 17 depicts the strain data for the middle of the upper wall (G6). The signals do not show a clear trend for how the various testing conditions affect the upper wall behavior. The strain oscillations, primarily in the partially filled tubes, could be explained by the lack of contact between the upper wall and the fluid; therefore, the structural vibrations are also measured by the gauge.

\subsection{Failure of the tanks}

The filling percentage and the impact velocity influence the failure of the tanks. When the tubes are impacted at lower velocities $(V=600 \mathrm{~m} / \mathrm{s})$ with different filling percentages, the main failure is located in the exit wall (Fig. 18). The projectile impacts the exit wall, and then the fluid transmits its kinetic energy deforming the wall and spreading the cracks. The cracks are longer when the tube has a higher filling percentage. Therefore, impacts at lower velocities are found to be more dangerous when the tank is completely filled. This could happen when a plane takes off.

When the tube is impacted at higher velocities $(V=900 \mathrm{~m} / \mathrm{s})$, in addition to the exit wall failure, the upper wall also fails if the tube is not completely filled (Fig. 19). The damage of the exit wall is larger when the impact occurs at high velocity and diminishes with the filling percentage, as occurs in the tubes impacted at $V=600 \mathrm{~m} / \mathrm{s}$. The failure of the upper wall does not appear when the tube is completely filled or the impact velocity is lower (Figs. 18 and 19a). Although it could be concluded that a lower filling percentage would allow the expansion of the fluid through the unfilled volume and thus, less damage to the tube, it is necessary to consider the acceleration of the layer of fluid raised by the cavity that impacts the upper wall causing failure (Fig. 19b and c). Therefore, an impact at high velocity in a partially filled tank could be 


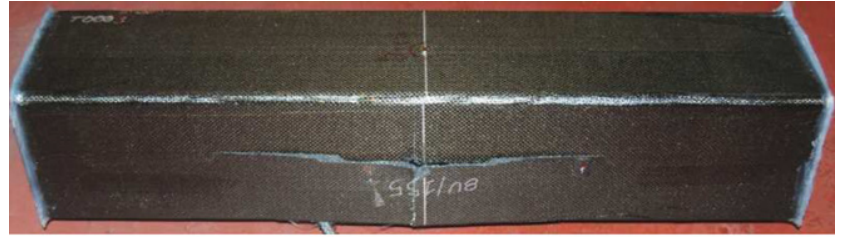

(a)

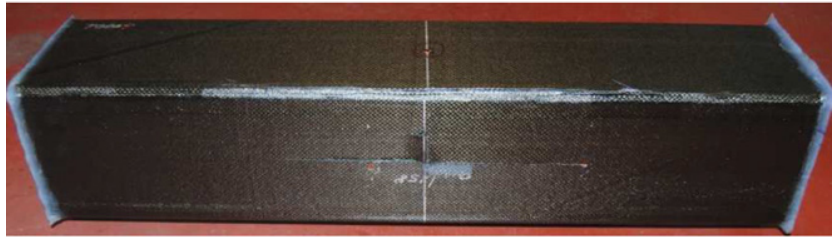

(b)

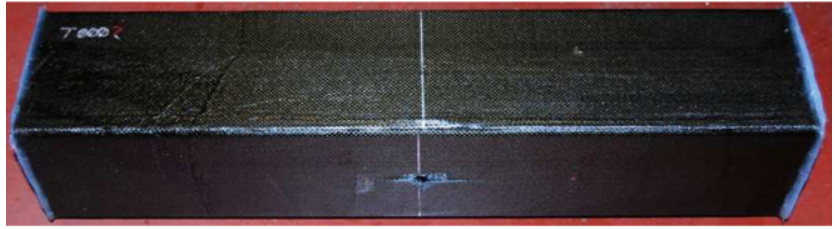

(c)

Fig. 18. Tubes impacted at $V=600 \mathrm{~m} / \mathrm{s}$ and different filling percentages: (a) $100 \%$. (b) $75 \%$. (c) $60 \%$.

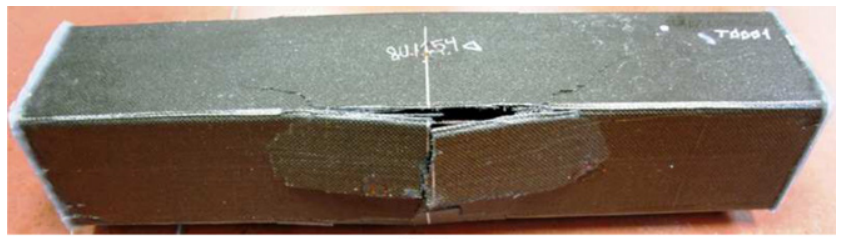

(a)

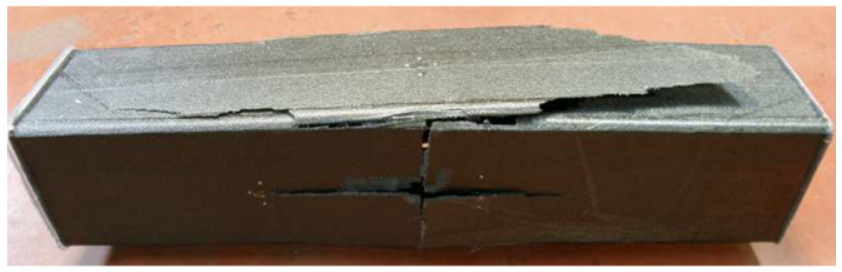

(b)

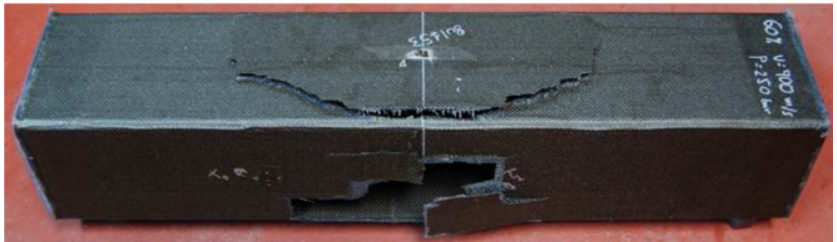

(c)

Fig. 19. Tubes impacted at $V=900 \mathrm{~m} / \mathrm{s}$ and different filling percentages: (a) $100 \%$. (b) $75 \%$. (c) $60 \%$

even more dangerous than an impact in a completely filled tank. When the tanks are completely filled and impacted at high velocity, a breakage in the lower wall edge appears (Fig. 20). The crack in the completely filled tubes is larger than in the partially filled tubes. The presence of a long crack in the border produces a smaller bulging of the lower wall, which would explain the smaller

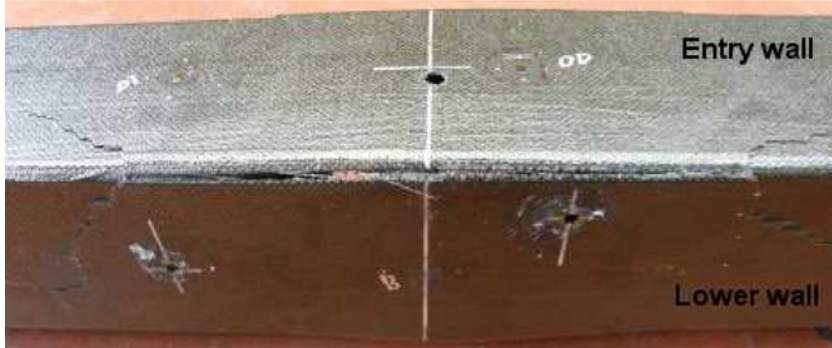

(a)

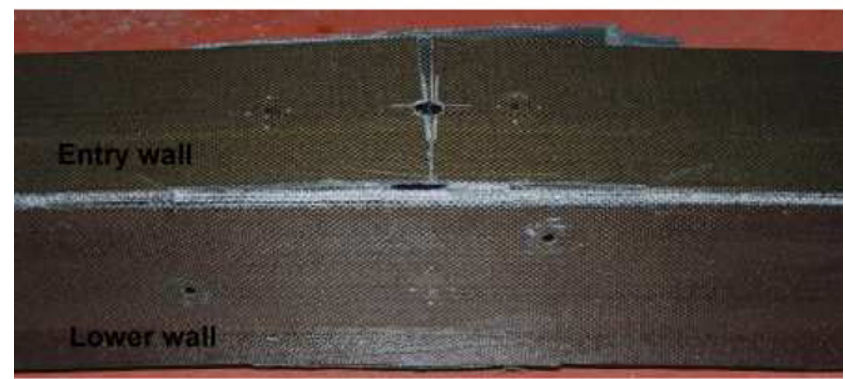

(b)

Fig. 20. Cracks in the lower wall border of tubes impacted at $V=900 \mathrm{~m} / \mathrm{s}$ : (a) $100 \%$. (b) $75 \%$.

strain value measure at $\mathrm{G} 5$ for the completely filled tubes impacted at $V=900 \mathrm{~m} / \mathrm{s}$ compared to the partially filled cases (Fig. 16).

\section{Conclusions}

CFRP square tubes filled with different levels of fluid were impacted by spherical steel projectiles at different velocities. A complete instrumentation of the specimens with pressure sensors and strain gauges and a recording of the penetration process of the projectile into the fluid allowed for the analysis of the HRAM phenomenon and the influence of the impact velocity and the filling percentage on the behavior of the tube, which led to the following conclusions:

- The presence of fluid inside the CFRP tube has a noticeable effect on the deformation and failure process after undergoing the impact of a high-velocity projectile because the fluid transmits the kinetic energy lost by the projectile when traveling through the fluid.

- When the tubes are partially filled, the wall, which initially is not in contact with the fluid, is deformed due to the impact of a layer of fluid generated by the cavity created behind the projectile. The deformation and failure of that wall depends not only on the projectile velocity but also on the kinetic energy of the layer of fluid. Consequently, the mass of the layer impacting the wall should be taken into account.

- The impact velocity and the filling percentage influence the deformation of the walls differently. The filling percentage affects the areas far from the impact, whereas the velocity seems to play an important role in points near the impact.

\section{Acknowledgements}

The authors would like to acknowledge the Center for the Development of Industrial Technology (CDTI) of Spain and to the company AERNNOVA Aerospace for the financial support for this 
research. We wish to express sincere gratitude to Mr. S. Puerta for his valuable help during the experimental testing.

\section{References}

[1] Tennyson RC. Composites in space - challenges and opportunities. Proc ICCM 10 1995; $1: 35-56$

[2] Airoldi A, Cacchione B. Modelling of impact forces and pressures in Lagrangian bird strike analyses. Int J Impact Eng 2006;32:1651-77.

[3] Anghileri M, Castelleti LML, Invernizzi F, Mascheroni M. A survey of numerical models for hail impact analysis. Int J Impact Eng 2005;31:929-44.

[4] Mines RAW, McKown S, Birch RS. Impact of aircraft rubber tyre fragments on aluminium alloy plates: I - Experimental. Int J Impact Eng 2007;34:627-46.

[5] Vasudev A, Meehlman J. A comparative study of the ballistic performance of glass reinforced plastic materials. SAMPLE Quart 1987;18:43-8.

[6] Cantwell WJ, Morton J. Influence of target geometry on the high velocity impact response of CFRP. Compos Struct 1988;10:247-65.

[7] Beaumont N, Penazzi L. The impact on a composite plate - a both theoretical and experimental approach of the inplane and transverse effects. Inst Phys Conf Ser 1989;102:411-8.

[8] Sun CT, Potti V. A simple model to predict residual velocities of thick composite laminates subjected to high velocity impact. Int J Impact Eng 1996;18:339-53.

[9] Bland PW, Dear JP. Observations on the impact behaviour of carbon-fibre reinforced polymers for the qualitative validation of models. Compos Part A: Appl Sci Manuf 2001;32:1217-27.

[10] López-Puente J, Zaera R, Navarro C. An analytical model for high velocity impacts on thin CFRPs woven laminates. Int J Solids Struct 2007:44:2837-51.

[11] Wen HM. Penetration and perforation of thick FRP laminates. Compos Sci Technol 2001;61:1163-72.

[12] López-Puente J, Varas D, Loya JA, Zaera R. Analytical modelling of high velocity impacts of cylindrical projectiles on carbon/epoxy laminates. Compos: Part A 2009;40:1223-30.

[13] Bland PW, Dear JP. Observations on the impact behaviour of carbon-fibre reinforced polymers for the qualitative validation of models. Compos Part A 2001;32:1217-27.

[14] López-Puente J, Zaera R, Navarro C. The effect of low temperatures on the intermediate and high velocity impact response of CFRP. Compos: Part B 2002;33:559-66.

[15] López-Puente J, Zaera R, Navarro C. Experimental and numerical analysis of normal and oblique ballistic impacts on thin carbon/epoxy woven laminates. Compos: Part A 2008;39:374-87.

[16] López-Puente J, Zaera R, Navarro C. High energy impact on woven laminates. J Phys IV 2003:639-44.

[17] Fernández-Fdz D, López-Puente J, Zaera R. Prediction of the behaviour of CFRPs against high-velocity impact of solids employing an artificial neural network methodology. Compos: Part A 2008;39:989-96.

[18] Hemmi K, Nishikawa M, Takeda N. Prediction of the foreign-object impact force on the composite fan blade. Des, Manuf Appl Compos 2008:101-8.

[19] Raimondo L, Iannucci L, Robinson P, Pinho ST. A numerical material model for predicting the high velocity impact behaviour of polymer composites. Mech Response Compos 2008;10:161-77.

[20] Nishikawa M, Okabe T, Takeda N. Numerical simulation of interlaminar damage propagation in CFRP cross-ply laminates under transverse loading. Int J Solids Struct 2007;44:3101-13.
[21] Hai-jun X, Rong-ren W. Aeroengine turbine blade containment tests using high-speed rotor spin test facility. Aerosp Sci Technol 2006;10:501-8.

[22] Lundstrom EA, Stull E. Fluid dynamic analysis of hydraulic ram II (Results of experiments), JTCG/AS 73-T-291. Joint Technical Coordinating Group/Aircraft Survivability.

[23] Bates KS Jr. Aircraft fuel tank entry wall-projectile interaction studies. Master's thesis, NPS; 1973.

[24] Holm DP. Hydraulic ram shock wave and cavitation effects on aircraft fuell cell survivability. Master's thesis, NPS; 1973.

[25] Soper WR. Hydraulic ram studies. Master's thesis, NPS; 1973.

[26] Fuhs AE, Ball RE, Power HL. Fy 73 hydraulic ram studies. NPS-57Fu74021, 1974.

[27] Mueller LS. Experiments in hydraulic ram. Master's thesis, NPS; 1974.

[28] Kappel LC. Hydraulic ram shock phase effects on fuel cell survivability, Master's thesis, NPS; 1974

[29] Power HL. Fy 74 experimental hydraulic ram studies. NPS-57Ph74081, 1974.

[30] Holm CM. Hydraulic ram presure measurements. Master's thesis, NPS; 1974.

[31] Page B. Entry wall strain measurements during hydraulic ram. Master's thesis, NPS; 1975.

[32] Patterson JW. Fuel cell pressure loading during hydraulic ram. Master's thesis, NPS; 1975.

[33] Power HL. Fy 75 experimental hydraulic ram studies. NPS-57Ph75061; 1975.

[34] Bless SJ, Barber JP, Fry PF, Newman RK. Studies of hydrodynamic ram induced by high velocity spherical fragment simulators. Technical report, AFML-TR-77$11,1977$.

[35] Avery JG. AGARD, design manual for impact damage tolerant aircraft structure. London, UK: Technical Editing and Reproduction Ltd.; 1981.

[36] Townsend D, Park N, Devall PM. Failure of fluid filled structures due to high velocity fragment impact. Int J Impact Eng 2003;29:723-33.

[37] Poehlmann-Martins F, Gabrys J, Souli M. Hydrodynamic ram analysis of nonexploding projectile impacting water. In: 2005 ASME pressure vessels and piping division conference, Denver, Colorado; 17-21 July 2005.

[38] Disimile PJ, Swanson LA, Toy N. The hydrodynamic ram pressure generated by spherical projectiles. Int J Impact Eng 2009;36:821-9.

[39] Lecysyn N, Bony-Dandrieux A, Aprin L, Heymes F, Slangen P, Dusserre G, et al. Experimental study of hydraulic ram effects on a liquid storage tank: analysis of overpressure and cavitation induced by a high-speed projectile. J Hazardous Materials 2010;178:635-43.

[40] Varas D, López-Puente J, Zaera R. Experimental analysis of fluid filled aluminium tubes subjected to high velocity impact. Int J Impact Eng 2009;36:81-91.

[41] Varas D, Zaera R, López-Puente J. Numerical modelling of the hydrodynamic ram phenomenon. Int J Impact Eng 2009;36:363-74.

[42] Nishida M, Tanaka K. Experimental study of perforation and cracking of waterfilled aluminum tubes impacted by steel spheres. Int J Impact Eng 2006;32:2000-16.

[43] Sparks CE, Hinrichsen RL, Friedmann D. Comparisson and validation of smooth particle hydrodynamic (SPH) and coupled euler lagrange (CEL) techniques for modeling hydrodynamic ram. In: 46th AIAA/ASME/ASCE/AHS/ASC structures, structural dynamics and materials conference, Austin, Texas; 18-21 April 2005.

[44] Gerhart PM, Gross RJ, Hochstein JI. Fundamentals of fluid mechanics. AddisonWesley Publishing Co.; 1992. 